\title{
Understanding relationships between the 1998 Yangtze River flood and northeast Eurasian blocking
}

\author{
Arthur N. Samel ${ }^{1, *}$, Xin-Zhong Liang ${ }^{2}$ \\ ${ }^{1}$ Geography/Environmental Programs, Bowling Green State University, Bowling Green, Ohio 43403, USA \\ ${ }^{2}$ Illinois State Water Survey, Department of Natural Resources and University of Illinois at Urbana-Champaign, \\ Urbana, Illinois 61820, USA
}

\begin{abstract}
Severe summer monsoon flooding occurred along the Yangtze River Valley (YRV) in 1998. The heaviest precipitation fell during June 8-23 and July 20-29 and coincided with midtropospheric blocking over northeast Eurasia. An index based on the difference between Okhotsk High and west Pacific Low intensity is developed in this study to quantify blocking; analysis shows that blocking and equatorward displacement of the upper-tropospheric east Asian jet preceded (accompanied) the June (July) period. This suggests that heavy rainfall during each interval was caused by different atmospheric processes. An examination of joint variations in the index and YRV precipitation during 1958-1998 revealed several periods similar to those identified in 1998. However, the exceptional magnitude of the blocking and rainfall during 1998 made the June and July events unique. During June 8-23, blocking collapsed and the jet retreated to its climatological position (approximately $35^{\circ} \mathrm{N}$ ) prior to heavy rainfall occurrence. The background vertical ascent of the jetinduced thermally direct circulation over the YRV was then enhanced by mid-tropospheric shortwave troughs that caused increased coupling between the lower- and upper-tropospheric circulations. In contrast, July 20-29 precipitation increased in response to intensification and anomalous equatorward displacement of the jet to a position just north of the YRV. Diminished mid-tropospheric ridging over central China further strengthened vertical ascent over the YRV. During both periods, the regional circulation acted to enhance tropical moisture transport, which, in turn, aided in precipitation production along the YRV.
\end{abstract}

KEY WORDS: Flood · Yangtze River Valley $\cdot$ Northeast Eurasian blocking $\cdot$ East Asian jet

\section{INTRODUCTION}

Yangtze River Valley (YRV) summer monsoon flooding in 1998 was the most severe to occur over the region since the devastating floods of 1954 and, in coastal areas, the worst experienced in the last $150 \mathrm{yr}$. Total precipitation, averaged along the lower reaches of the Yangtze River $\left(28-32^{\circ} \mathrm{N}, 105-122.5^{\circ} \mathrm{E}\right)$ between May 15-August 5 was $733.4 \mathrm{~mm}$ (Fig. 1). This represented a $191.7 \mathrm{~mm}$ positive anomaly for the period. Extremely high Yangtze River levels associated with the excessive rainfall led to the deliberate destruction of a large number of levees upriver from Wuhan $\left(30^{\circ} 37^{\prime} \mathrm{N}, 114^{\circ} 08^{\prime} \mathrm{E}\right)$ in an attempt to spare this vital industrial center from inundation. While Wuhan was ultimately saved, extensive damage occurred throughout the region. Monetary losses approached $\$ 30$ billion; 25 million ha of farmland were inundated, 5 million homes were destroyed and an additional 12 million homes were damaged. In addition, approximately 3700 people lost their lives, while 223 million others were displaced (NCDC 1999).

The climatological onset of the summer monsoon over the YRV occurs in mid-June, when the east-west- 
oriented monsoon rain band jumps abruptly from southeast China to approximately $30^{\circ} \mathrm{N}$ (Tao \& Chen 1987, Samel et al. 1999). During the period that the rain band is located along the YRV, it acts as a weak thermal boundary and is called the Mei-yu front. The Meiyu front focuses precipitation in the YRV as moisture transported from the South China Sea and tropical Pacific and Indian oceans overruns cooler air to the north. In addition, the migration of mid-tropospheric disturbances along the front acts to enhance rainfall along the YRV (Samel et al. 1995). The Mei-yu front persists along the YRV until mid-July, at which time it quickly shifts to northeast China (Samel et al. 1999).

The heaviest rainfall in 1998 occurred during June 8-23 and July 20-29, when regionally averaged daily totals approached $40 \mathrm{~mm}$ (Fig. 2). Although the 2 intervals coincided with climatologically active monsoon periods over the YRV and northeast China, respectively (Lau et al. 1988, Samel et al. 1999), rainfall during several days exceeded 4 times the mean amount. Therefore, it is important to distinguish between mean and anomalous monsoon characteristics. In particular, we focus on the 4 most intense episodes, which occurred during June 8-12, June 20-23, July 20-23 and July 29.

The east Asian monsoon is a highly complex system, where YRV rainfall has been shown to be sensi- tive to sea-surface temperature (SST) variations over the Pacific and Indian oceans as well as the South China Sea. The 1998 event coincided with the occurrence of positive SST anomalies over the subtropical west Pacific Ocean and an abrupt transition from El Niño to La Niña conditions. Weng et al. (1999) found that interannual and decadal modes of subtropical west Pacific SST variations are positively correlated with YRV rainfall. Lau \& Weng (2001) and Lau \& Wu (2001) identified a biennial tendency in basin-scale SST anomalies during the transition between El Niño and La Niña to explain the 1998 YRV rainfall. In addition, both Lau \& Wu (2001) and Shen et al. (2001) showed that anomalous SSTs over the Pacific and Indian Oceans explained westward expansion of the west-central Pacific subtropical high (Fig. 3a) and heavy YRV rainfall during the 1998 summer monsoon.

The above literature contributes substantially to our understanding of large- and planetary-scale mechanisms that impact the east Asian monsoon system. The purpose of the current study is to address daily variations in the regional Eurasian circulation that produced excessive YRV rainfall in 1998.

Two Eurasian circulation features that have been used extensively to explain monsoon variability are the

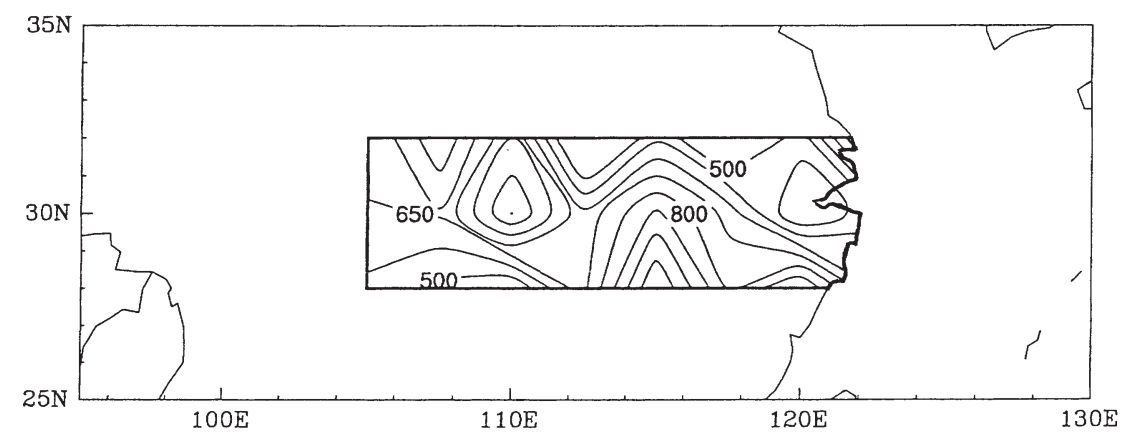

Fig. 1. Total precipitation along the Yangtze River Valley (YRV; $\left.28-32^{\circ} \mathrm{N}, 105-122.5^{\circ} \mathrm{E}\right)$ during the period May $15-\mathrm{August} 5$, 1998. The contour interval is $150 \mathrm{~mm}$

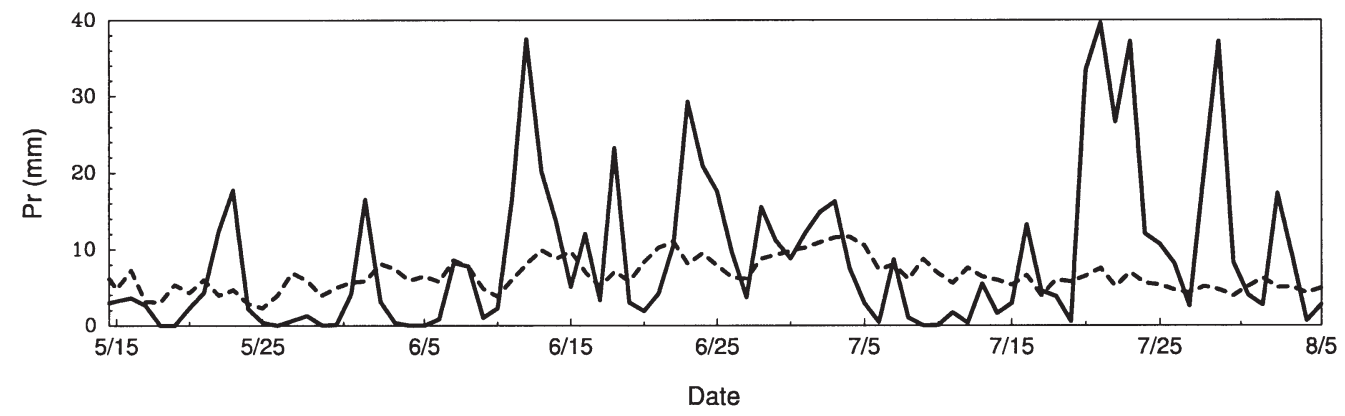

Fig. 2. May 15-August 5 daily time series of YRV 1998 precipitation ( $m$ m; solid line) and mean precipitation (dashed line) 
west central Pacific subtropical high and upper-tropospheric east Asian jet stream. The climatological location of the subtropical-high axis when the monsoon rain band is located along the YRV is approximately $25^{\circ} \mathrm{N}$ (Samel et al. 1999; Fig. 3a). During this period, the Mei-yu front acts as a weak thermal boundary that focuses rain-band precipitation. The subtropical high acts to block equatorward movement of the Mei-yu front (Chang \& Chen 1995, Chang et al. 2000a,b) and determines the poleward extent of precipitation over China (Tao \& Chen 1987), where anomalous westward ridging of the high causes tropical moisture transport and rainfall to increase along its northern and western flanks (Yatagai \& Yasunari 1995, Fan \& Oglesby 1996, Nitta \& Hu 1996, Samel et al. 1999, Shen et al. 2001). The progressive weakening and northward retreat of the east Asian jet stream (Fig. 3b) is identified with the poleward advance of the monsoon rain band (Tao \& Chen 1987). This results from the jet-induced thermally-direct meridional cell, which straddles the entrance region and merges with the ascending branch of the Hadley circulation (Fig. 3c; Liang \& Wang 1998, Lau et al. 2000). This feature contributes to both the climatological state and interannual variations (Liang \& Wang 1998, Liang et al. 2001).

An initial analysis of the Eurasian circulation shows that equatorward displacement and anomalous westward ridging of the subtropical high occurred in conjunction with the June 8-12 episode. This is consistent with Lau \& Wu (2001) and Shen et al. (2001). On the other hand, the east Asian jet was unusually intense and located to the south of its mean position during both July episodes. Because neither mechanism can fully explain YRV heavy rainfall occurrence for all episodes, additional processes must be considered. In particular, we found that mid-tropospheric blocking over northeast Eurasia was present immediately before or during the 4 episodes. The blocking consisted of the Okhotsk High $(\mathrm{OH})$ and its counterpart, the west Pacific Low (WPL). The OH resides over the Sea of Okhotsk and northeast Siberia during June and July (Fig. 3a). It has been shown to block the eastward progression of short-wave troughs along the northern periphery of the Tibetan Plateau, steer these transient disturbances into the YRV (Ding 1994) and, consequently, enhance local monsoon rainfall (Samel et al. 1995, 1999).

The purpose of this study is to identify relationships during summer 1998 between YRV heavy rainfall and northeast Eurasian blocking and to elaborate on the dynamical mechanisms that triggered the precipitation. Specifically, we will first develop an index to quantify blocking and then determine the characteristic Eurasian circulations that explain distinct relationships during the June and July intense precipitation

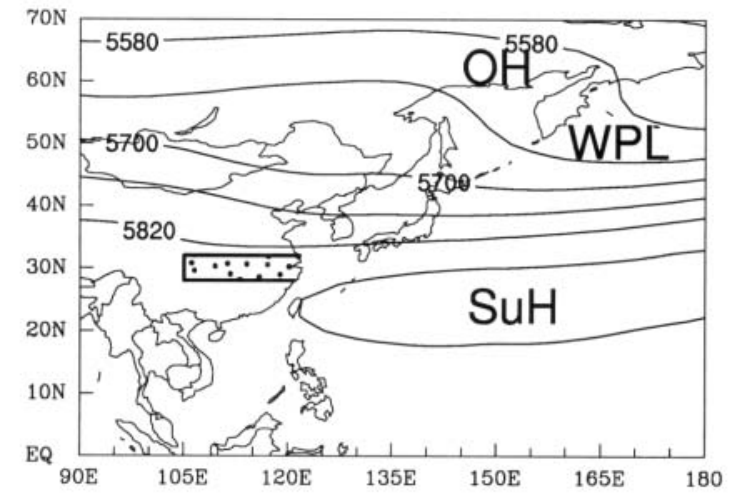

(a)

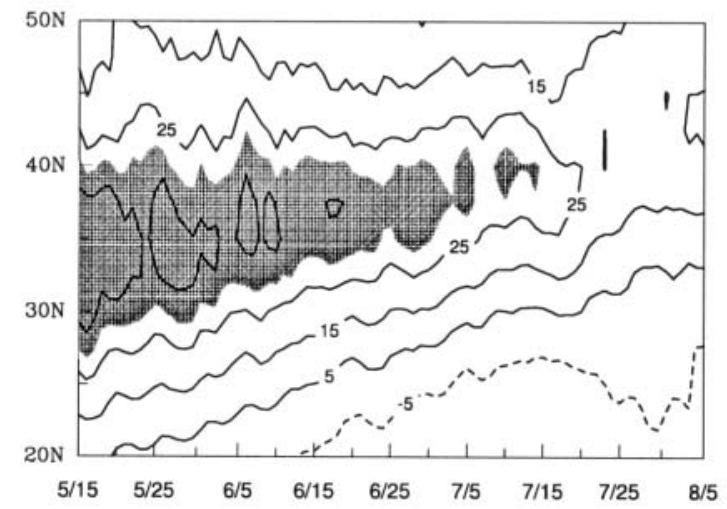

(b)

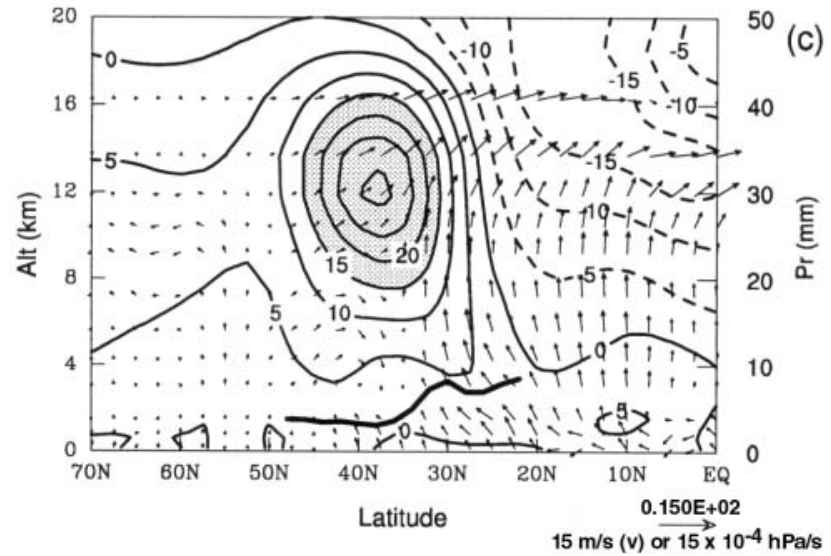

Fig. 3. (a) June 15-July 15 mean $500 \mathrm{hPa}$ height $\left(H_{500}\right.$ m), where the YRV is outlined and dots represent the stations used to calculate regional rainfall. Okhotsk High $(\mathrm{OH})$, west Pacific Low (WPL) and subtropical high (SuH) locations are also shown. (b) Time-latitude cross-section of zonally averaged $\left(105-122.5^{\circ} \mathrm{E}\right)$ 1979-98 mean $200 \mathrm{hPa}$ zonal wind $\left(U_{200}\right)$. Shading indicates values greater than $30 \mathrm{~m} \mathrm{~s}^{-1}$. (c) June 15-July 15 mean latitude-altitude cross-section of the zonally averaged 3-dimensional wind. The zonal $\left(\mathrm{m} \mathrm{s}^{-1}\right)$, meridional $\left(\mathrm{m} \mathrm{s}^{-1}\right)$ and vertical $\left(10^{-4} \mathrm{hPa} \mathrm{s}^{-1}\right)$ components are represented by contours and vectors, respectively. Solid (dashed) curves indicate positive (negative) zonal winds, where shading depicts values greater than $15 \mathrm{~m} \mathrm{~s}^{-1}$. Zonally averaged precipitation over east China ( $\mathrm{mm} \mathrm{d}^{-1}$; heavy solid curve) is given along the right-hand $y$-axis 
episodes. Note that a discussion of the mechanisms that cause northeast Eurasian blocking variations is beyond the scope of this work and will not be presented in the study.

\section{DATA PREPARATION}

The 1998 YRV daily rainfall time series is developed between May 15 and August 5 and given as the 12 -station average for the zonal band $28-32^{\circ} \mathrm{N}, 105-122.5^{\circ} \mathrm{E}$ (Fig. 3a). The anomaly for a specific day is the difference between the 1998 value and the 1979-98 mean, where the long-term time series at each location is constructed from 3 separate archives (Tao et al. 1991, National Climate Data Center 1999) and tested to assure consistency and continuity. This 'zonal band' time series is utilized because summer monsoon precipitation is typically zonally aligned and the Yangtze River flows along the $30^{\circ} \mathrm{N}$ parallel. Zonal band time series have also been used in previous monsoon investigations to identify relationships between east China rainfall and large-scale circulation variations on annual (Liang \& Wang 1998), interannual (Samel et al. 1995, 1999) and decadal (Liang et al. 1995) time scales. To assess 1998 east China precipitation, station data will be utilized, as above, to construct zonally averaged daily rainfall time series for $4^{\circ}$ latitude overlapping bands, from $20-24^{\circ} \mathrm{N}$ to $46-50^{\circ} \mathrm{N}$.

NCEP/NCAR reanalysis data (Kalnay et al. 1996) are used to quantify blocking over northeast Eurasia as well as to develop relationships between YRV rainfall variations and general circulation evolution. The fields considered include sea-level pressure $\left(P_{\mathrm{s} 1}\right), 500 \mathrm{hPa}$ height $\left(H_{500}\right), 200$ and $850 \mathrm{hPa}$ divergence $\left(D_{200}\right.$ and $D_{850}$, respectively), $200 \mathrm{hPa}$ zonal wind $\left(U_{200}\right)$ and the zonally averaged $\left(105-122.5^{\circ} \mathrm{E}\right) 3$-dimensional wind over east Asia $\left(0-70^{\circ} \mathrm{N}\right)$. The reanalysis data are utilized for a Eurasian domain $\left(0-70^{\circ} \mathrm{N}, 90-180^{\circ} \mathrm{E}\right)$ between $1979-98$ on a regularly-spaced $2.5^{\circ}$ latitudelongitude grid. The anomaly for a specific field, point and day is defined as the difference between the grid value and the 1979-98 mean for that date. The zonal and meridional wind components are given at 17 pressure levels, while the vertical component is available for the lower 12 levels.

\section{BLOCKING INDEX AND THE EAST ASIAN JET}

The northeast Eurasian blocking index (NBI) is developed in this study to provide a measure of midtropospheric variations attributed to the OH and WPL. It is defined to be the daily difference between areaaveraged $H_{500}$ anomalies over northeast Siberia and the adjacent northwest Pacific, where the center of each region (see Fig. 3a) corresponds approximately to that of the June 15-July 15 mean $\mathrm{OH}$ and WPL, respectively. Thus, a large positive NBI indicates amplified blocking, while negative values denote low amplitude or reversed phase features.

Fig. 4 shows the May 15-August 5 YRV precipitation anomaly and NBI daily time series as well as the $U_{200}$ anomaly Hovmöller (latitude-time) diagram. Index values (Fig. 4a) increased steadily and the jet (Fig. 4b) moved to the south between mid-May and early June. The NBI reached its maximum on June 8 and was followed by an abrupt decrease, which indicates the collapse of blocking. This occurred in conjunction with the onset of YRV heavy rainfall on June 10; the maximum was observed on June 12. Meanwhile, the jet returned to its mean position on June 10 and near-normal $U_{200}$ over much of east China accompanied YRV heavy rainfall between June 10-15. This cycle was repeated approximately 2 wk later, when the secondary NBI peak on June 20 preceded the poleward retreat of the jet and intense YRV precipitation on June 23. The results clearly illustrate a lagged relationship, in which blocking decreased rapidly and the jet retreated to the north prior to the occurrence of YRV heavy rainfall.

Precipitation diminished along the YRV between June 25 and July 16. During this period, the NBI was negatively correlated with modest YRV rainfall anomalies (Fig. 4a). The $U_{200}$ anomaly pattern (Fig. 4 b) indicates an approximate $10^{\circ}$ poleward jump of the jet, which was accompanied by increased north China rainfall (not shown). It is not apparent whether the poleward shift of the jet and precipitation on June 25 was a necessary dynamic transition between the June and July heavy rainfall regimes. This issue will be addressed in a future study.

The jet then moved abruptly south of its mean position to approximately $37.5^{\circ} \mathrm{N}$ on July 17 and remained stationary through early August. This persistent pattern was identified with near-continuous YRV rainfall along the southern flank of the jet. Meanwhile, the NBI increased rapidly after July 15, reached its maximum on July 23 and depicts the establishment of blocking. The blocking intensity varied in-phase with both YRV rainfall and the amplitude of the positive jet anomaly during July 20-29.

The above analysis reveals different modes of variation between the NBI and YRV precipitation during June 8-23 and July 20-29. This signals the existence of contrasting mid-tropospheric circulation and polar jet structures and suggests that distinct atmospheric processes produced YRV heavy rainfall in June and July. An analysis of the 1958-1998 NBI and YRV precipitation time series between May 15 and August 5 

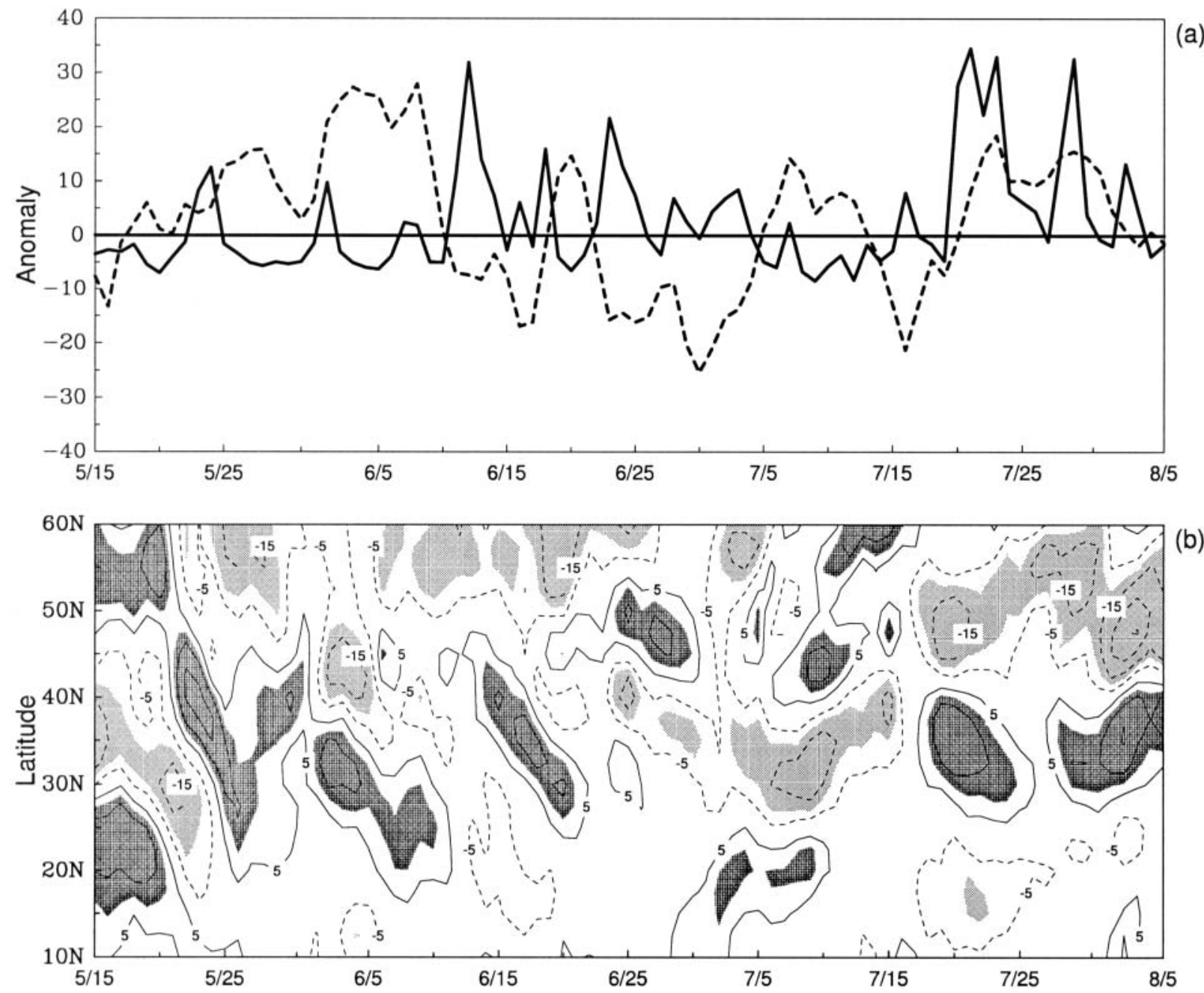

Fig. 4. (a) The May 15-August 5, 1998, YRV rainfall anomaly (mm; solid line) and NBI (m/10; dashed line) daily time series and (b) latitude-time diagram of $U_{200}\left(\mathrm{~m} \mathrm{~s}^{-1}\right)$. Dark (light) shading indicates values greater (less) than $10(-10) \mathrm{m} \mathrm{s}^{-1}$

was performed to determine whether these modes of variation occurred in the historical record. Results revealed several periods that were very similar to those identified during 1998. However, in no instance during the $41 \mathrm{yr}$ period was the blocking as intense or the rainfall as heavy as that recorded in 1998 . Thus, the 1998 events were unique.

Given the large distance that separates the NBI region and YRV, it is unlikely that blocking variations directly caused the heavy precipitation. Instead, we believe that the blocking contributed to the dynamical processes that triggered the rainfall. Although identification of the linkages that exist between the NBI and these dynamical mechanisms is an important issue, it is beyond the scope of the current investigation and will be addressed in the future. Thus, the purpose of the next 2 sections is to elaborate on Eurasian circulation evolution during June 8-23 and July 20-29 and iden- tify the specific processes that explain the occurrence of YRV heavy rainfall.

\section{EURASIAN CIRCULATION DURING JUNE 8-23}

Fig. 5 shows Eurasian circulation characteristics on June 8 , when the NBI maximum occurred. Both the $H_{500} \mathrm{OH}$ and WPL were highly amplified (Fig. 5a) and accompanied by mid-latitude troughs over south central and far northeast China. Meanwhile, anomalous westward ridging of the subtropical high existed over the South China Sea. The tropospheric divergence field over east China was governed by the mid-latitude troughs, where positive $D_{200}$ (Fig. $5 \mathrm{~b}$ ) and negative $D_{850}$ (Fig. 5c) were located to the east of the trough axes. Maximum $D_{200}$ was found along the lower reaches of the YRV, while minimum $D_{850}$ was centered 


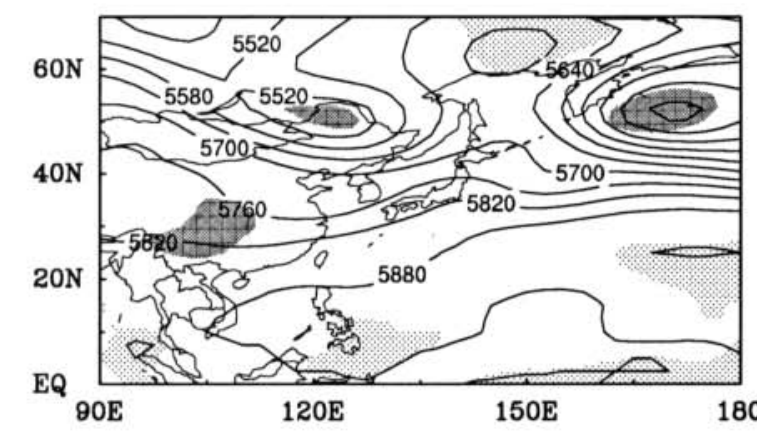

(a)

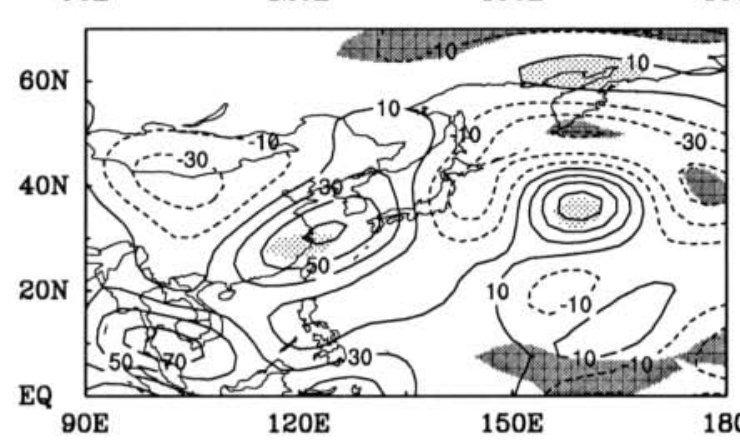

(b)

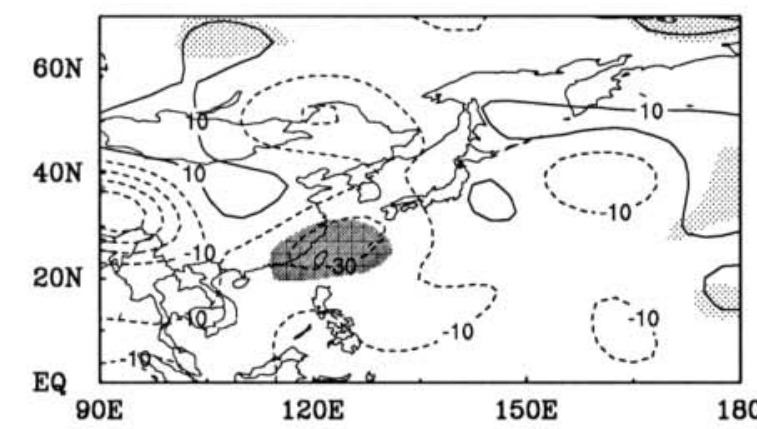

(c)

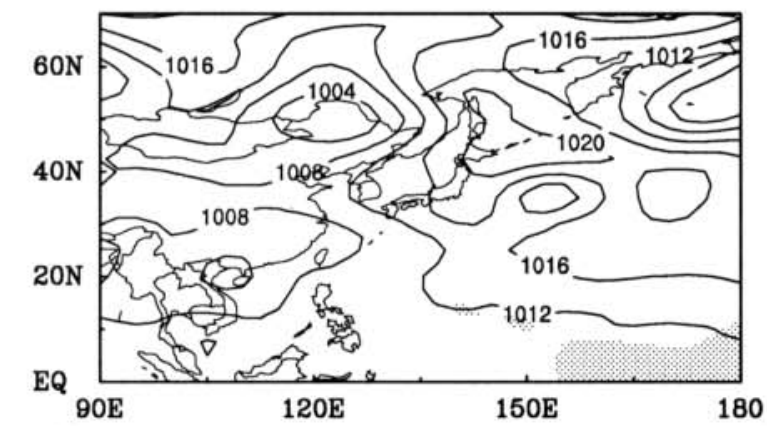

(d)

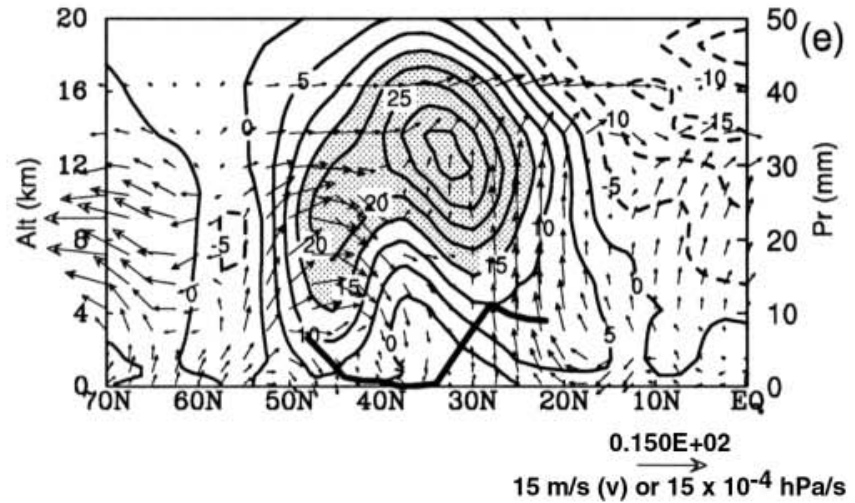

approximately $5^{\circ}$ to the south and coincided with the lowest surface pressure (Fig. 5d). The occurrence of positive $D_{200}$ and negative $D_{850}$ to the south of the YRV indicates coupling between the upper and lower tropospheric circulations and results in enhanced upward motion (Chang et al. 1998). This is clearly seen in Fig. 5e.

The east Asian jet was located to the south of its mean position and anomalously intense, where maximum winds exceeded $35 \mathrm{~m} \mathrm{~s}^{-1}$ (Fig. 5e). The YRV was beneath the jet entrance region (not shown), where the ascending branches of the direct and Hadley circulations, coupling, and the heaviest rainfall occurred south of the YRV $\left(20-27.5^{\circ} \mathrm{N}\right)$. A closer inspection of Figs. 5c-e shows that low-level convergence between 20 and $27.5^{\circ} \mathrm{N}$ was focused along a boundary which separated relatively cool easterlies of Pacific origin to the north from tropical southwesterlies that originated over the South China Sea and Indochina (e.g. Chen \& Li 1995). The poleward transport of moisture along the periphery of the anomalous subtropical high aided in precipitation production over the low-level boundary (Shen et al. 2001), which, in turn, was maintained by the cyclonic circulation around the south China $P_{\mathrm{sl}}$ low (e.g. Ma \& Bosart 1987). The results show that heavy rainfall south of the YRV was produced by vigorous ascent that was generated by the anomalous polar jet and amplified by the south central China trough. The jet contribution is similar to that described by Liang \& Wang (1998) and Lau et al. (2000), while amplification due to the mid-tropospheric troughs agrees with Chang et al. (1998), Chen \& Li (1995) and Ninomiya \& Akiyama (1992).

From June 8 to 12, blocking steadily decreased where the $\mathrm{OH}$ migrated to the dateline, a $H_{500}$ low formed over northeast Siberia and a second high became established in southeast Siberia (Fig. 6a). The westward extension of the subtropical high moved $10^{\circ}$ north to approximately $20^{\circ} \mathrm{N}$. A new mid-latitude trough formed over western Mongolia (approximately $95^{\circ} \mathrm{E}$ ) and curved toward northeast China and along the east coast. The east China portion of the trough acted to increase coupling along the lower reaches of the YRV (Fig. 6b,c). Stronger coupling coincided with the presence of the surface low (Fig. 6d), where the cyclonic circulation around this feature maintained a

Fig. 5. June 8,1998 , (a) mean $500 \mathrm{hPa}$ height $\left(H_{500} ; \mathrm{m}\right)$, (b) $200 \mathrm{hPa}$ divergence $\left(D_{200} ; \mathrm{s}^{-1} \times 10^{7}\right)$, (c) $850 \mathrm{hPa}$ divergence

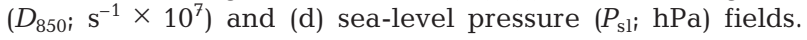
Light (dark) shading indicates anomalies greater (less) than 1.5 SD above (below) the 1979-98 June 8 mean. Solid and dashed curves in (b) and (c) depict positive and negative values, respectively. (e) Latitude-altitude cross-section of the zonally averaged 3-dimensional wind field and east China precipitation (see Fig. 2c for details) 
Mei-yu frontal boundary that separated low-level Pacific easterlies from South China Sea southwesterlies (Fig 6e). Both southwest flow and tropical moisture transport were enhanced as far north as the YRV by the poleward migration of the subtropical high (Shen et al. 2001). The ascending branch of the direct circulation and maximum rainfall were located along the YRV, where jet position and intensity were nearly identical to climatological means (Fig. 3b). Hence, coupling caused by the trough enhanced the background upward motion of the ascending branch of the jetinduced direct circulation and, as a consequence, anomalously heavy YRV rainfall was produced along the Mei-yu front on June 12.

The circulation patterns identified with the June 8-12 episode were almost identically reproduced during June 20-23. Blocking characteristics over northeast Eurasia as well as polar jet and mid-tropospheric trough placement over China differed little and affirm that the same physical processes dominated both episodes. However, anomalous subtropical high characteristics were absent between June 20 and 23. This coincided with a smaller rainfall peak and confirms that tropical moisture transport along the northwest flank of the subtropical high assisted the dominant processes outlined above in the production of heavier precipitation during June 8-12.

\section{EURASIAN CIRCULATION DURING JULY 20-29}

Fig. 7 shows Eurasian circulation characteristics on July 20. A deep $H_{500}$ low was located over northeast Siberia (Fig. 7a) and indicates that the negative NBI was due primarily to the absence of the $\mathrm{OH}$. Additional features included a second low in northeast China, a ridge along $100^{\circ} \mathrm{E}$, a high above central Siberia, and the subtropical high, which was anomalously strong and centered at $40^{\circ} \mathrm{N}$, well to the north of its mean position. Both $D_{200}$ and $D_{850}$ (Fig. $7 \mathrm{~b}, \mathrm{c}$ ) over east China were negative while surface low pressure (Fig. 7d) covered a broad area along and north of the YRV. The above fields do not indicate highly favorable conditions for upward motion, due to the presence of the central China ridge and a consequent lack of coupling (i.e. negative $D_{850}$ and $D_{200}$ ) over east China.

The polar jet (Fig. 7e) was centered at $37.5^{\circ} \mathrm{N}$, approximately $5^{\circ}$ south of the July 20 mean, where the maximum zonal wind anomaly exceeded $15 \mathrm{~m} \mathrm{~s}^{-1}$ (Fig. 4b). Given minimal coupling between the upperand lower-tropospheric circulations over east China, the anomalous jet and its direct circulation clearly played a dominant role in the generation of upward motion in the YRV. This maintained low-level convergence along the Mei-yu front, where flow to the south

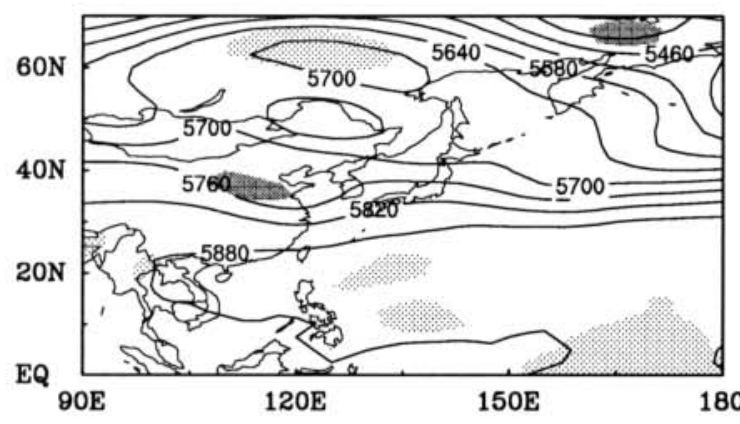

(a)

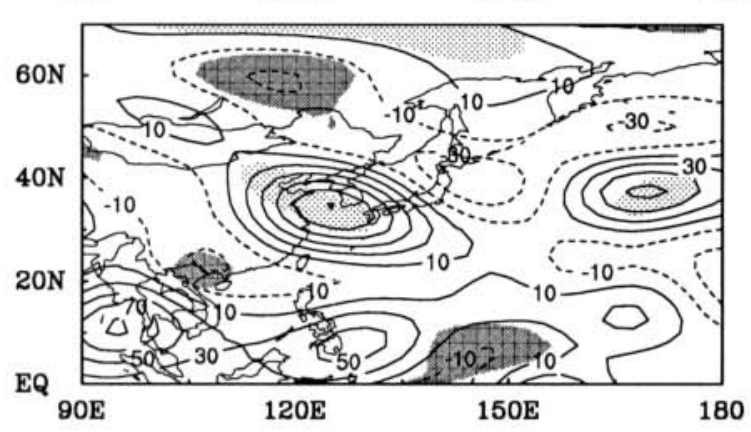

(b)

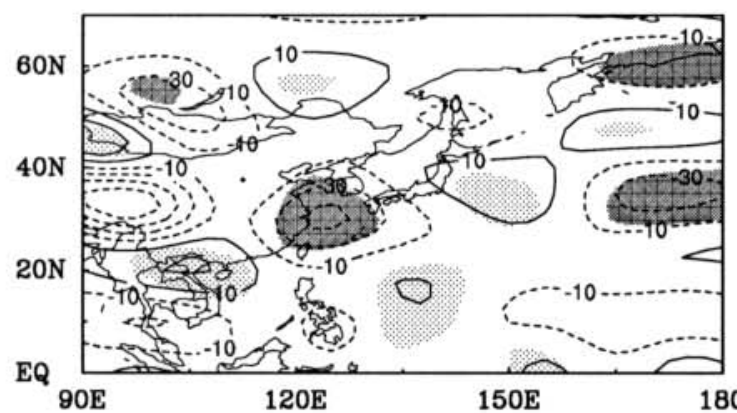

(c)

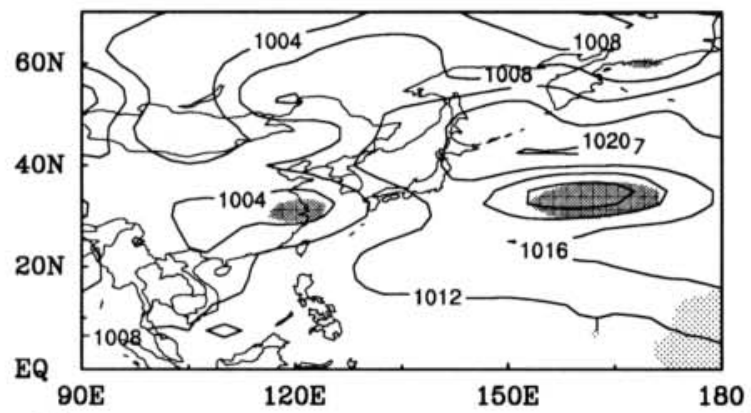

(d)

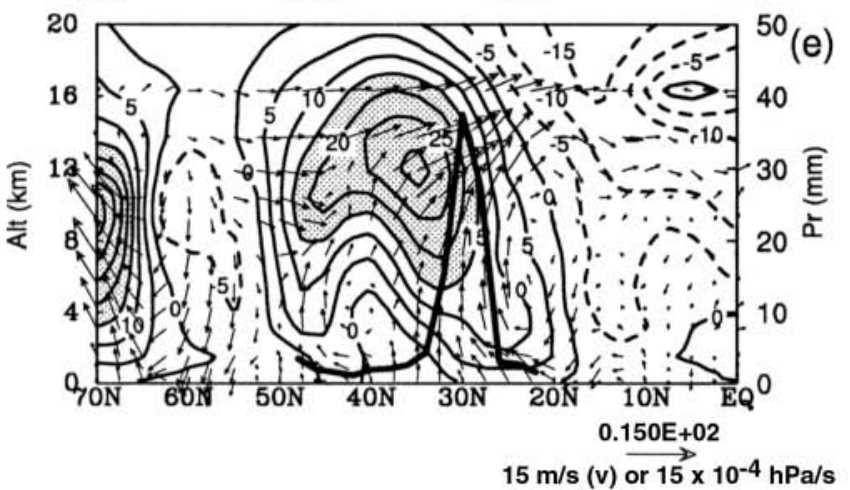

Fig. 6. Same as Fig. 5 except for June 12, 1998 


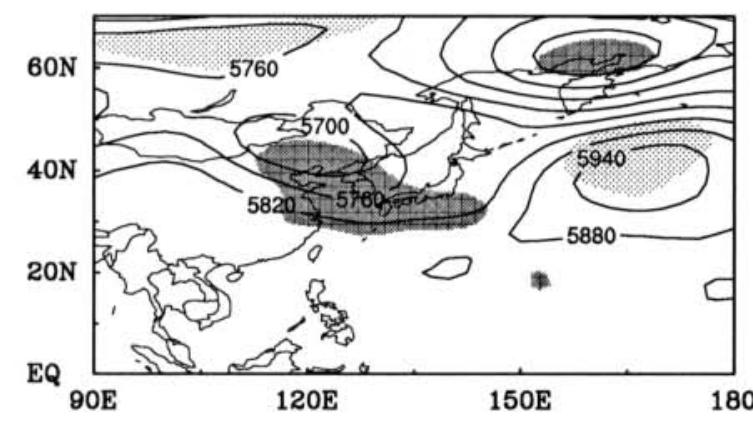

(a)

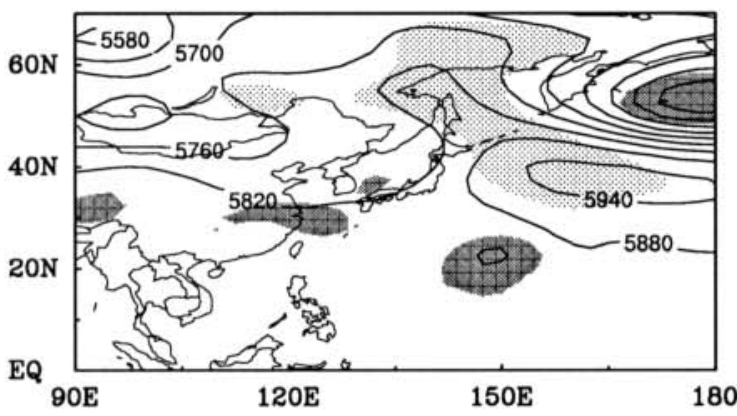

(a)

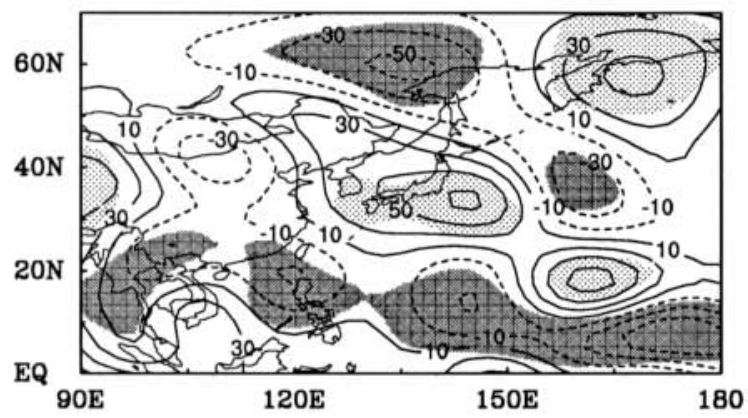

(b)

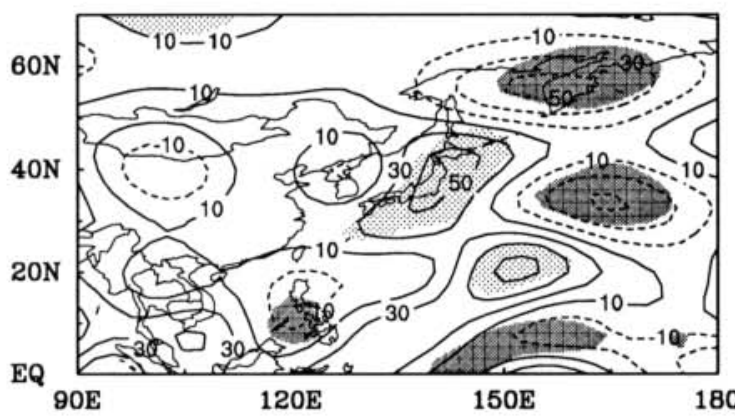

(b)

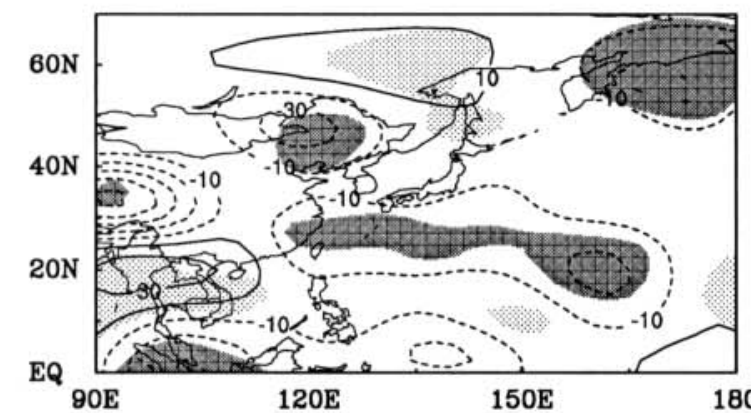

(c)

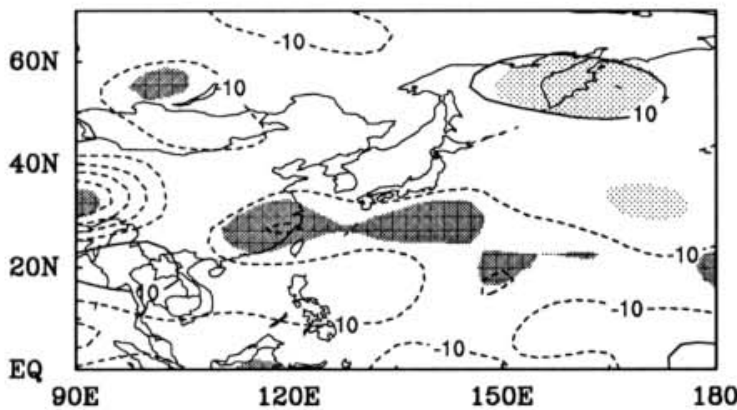

(c)

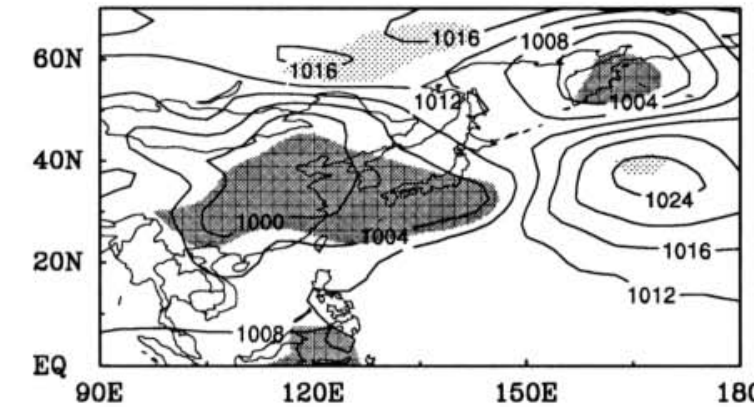

(d)
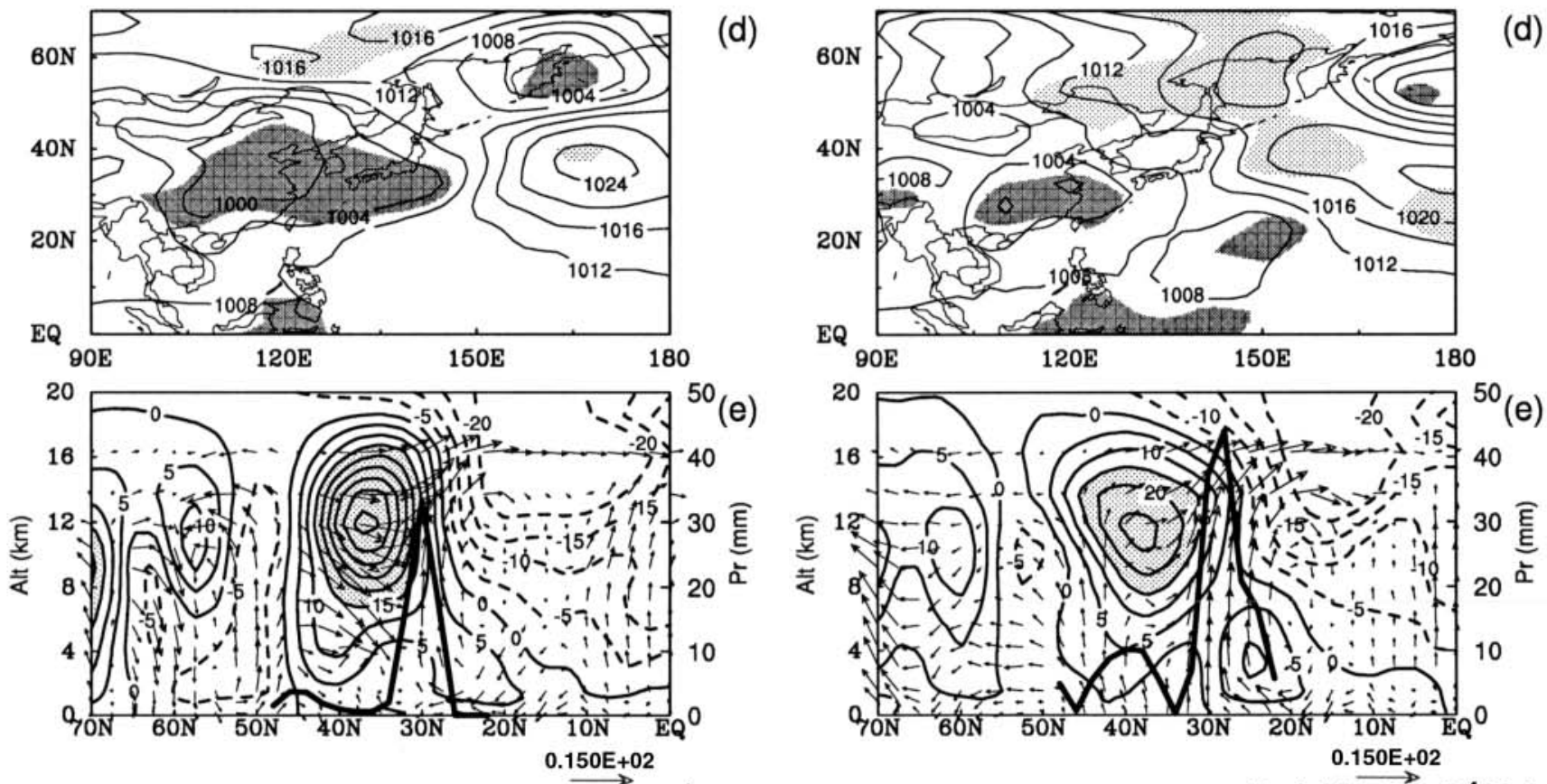

$15 \mathrm{~m} / \mathrm{s}$ (v) $\overrightarrow{\text { or } 15} \times 10^{-4} \mathrm{hPa} / \mathrm{s}$

Fig. 7. Same as Fig. 5 except for July 20, 1998

Fig. 8. Same as Fig. 5 except for July 23, 1998 
of the front transported tropical moisture from the South China Sea and Indochina. The relationship between the polar jet and YRV precipitation production on July 20 is consistent with Liang \& Wang (1998).

The NBI grew steadily during July 20-23 as a result of $\mathrm{OH}$ and WPL intensification (Fig. 8a); the index maximum on July 23 coincided with continued YRV heavy rainfall (Fig. 4a). In addition, the northeast China low and the ridge at $100^{\circ} \mathrm{E}$ weakened substantially, while the subtropical high axis became elongated and appeared to merge with the $\mathrm{OH}$. The lower amplitude of the mid-latitude $H_{500}$ features allowed small positive $D_{200}$ to become established in east China (Fig. 8b). This coincided with negative $D_{850}$ over southeast China (Fig. 8c) and indicates that modest coupling between the upper- and lower-tropospheric circulations became established along and south of the YRV.

Minimum $P_{\mathrm{sl}}$ occurred on an axis that paralleled the YRV (Fig. 8d), although the July 23 central pressure was slightly higher than that on July 20. The 3-dimensional wind cross-section (Fig. 8e) shows both intensified ascent and rainfall within this band, where the heaviest precipitation $(44.1 \mathrm{~mm})$ fell just south of the YRV. The cross-section also shows that, relative to July 20 , the jet weakened to approximately $25 \mathrm{~m} \mathrm{~s}^{-1}$. Although the diminished jet would be expected to have a negative impact on vertical ascent between 25 and $30^{\circ} \mathrm{N}$, there was a clear increase in upward motion. This occurred as a consequence of greater coupling between the upper- and lower-tropospheric circulations along and south of the YRV. The results signal a strong link between increased $D_{200}$ over east China and both greater ascent and heavy rainfall along and south of the YRV.

Although the NBI remained positive through early August, both blocking and YRV precipitation diminished during July 25-27 (Fig. 4a). This was followed on July 29 by a second NBI maximum and renewed heavy rainfall $(37.2 \mathrm{~mm})$. The rapid increase in the NBI on July 29 differed little from that observed during July 20-23. In addition, the position and intensity of the polar jet, as well as the location of the mid-tropospheric ridge over central China and surface low along the YRV, were very similar. These indicate that virtually identical physical processes dominated both episodes.

\section{SUMMARY AND DISCUSSION}

Flooding along the YRV during summer 1998 was identified with the occurrence of periodic northeast Eurasian blocking. The NBI daily time series was developed in this study to quantify blocking amplitude and its variations. Analysis shows different modes of variation between the NBI and YRV precipitation, where blocking preceded (accompanied) heavy rainfall during June 8-23 (July 20-29). Our result signals that distinct mid-tropospheric circulation and polar jet structures prevailed over Eurasia during each period. An examination of joint NBI and YRV precipitation variations during 1958-1998 identified several periods with similar characteristics to those identified in 1998. However, blocking magnitude and YRV rainfall intensity in 1998 revealed the June and July events to be unique.

The NBI began to increase in late May and reached its maximum on June 8. This coincided with the progressive equatorward advance of the jet. Blocking then collapsed and the jet retreated to its mean position as YRV heavy precipitation began on June 10 and peaked on June 12. The same cycle was repeated during June 20-23. Both episodes are identified with $H_{500}$ short-wave troughs in east China that enhanced tropospheric coupling and amplified the background ascent of the east Asian jet direct circulation. However, anomalous westward ridging of the subtropical high between June 8 and 12 contributed to greater tropical moisture transport and heavier rainfall during this period.

After a break in the monsoon precipitation, the NBI increased and YRV heavy rainfall resumed on July 20. The Eurasian circulation did not favor local upward motion, because a $H_{500}$ ridge at $100^{\circ} \mathrm{E}$ limited coupling throughout east China. However, the polar jet during July 20-23 was anomalously intense and located south of its mean position. As a result, both the ascending branch of the direct circulation and rainfall increased over the YRV. The heaviest rainfall occurred on July 23, when the ridge diminished and increased coupling-enhanced upward motion. The circulation features during the July 29 episode were nearly identical to those on July 23.

Our results suggest that, during June, northeast Eurasian blocking forced short-wave troughs into the YRV, which enhanced the ascending branch of the direct circulation to the south of the east Asian jet and produced heavy rainfall. On the other hand, in July, increased blocking coincided with an equatorward shift of the polar jet, which enhanced both upward motion and precipitation along the YRV. During each month, a near-identical repetition of the respective features led to a second rainfall peak. In addition, tropical moisture transport from the South China Sea and Indochina was identified as a crucial component in heavy YRV rainfall production in each of the June and July episodes.

The results of the current study have raised 3 important research questions that will be addressed in future investigations. First, what caused the NBI to vary in June and July 1998? Second, what direct linkages 
existed between the NBI and the dynamical mechanisms that triggered the YRV heavy rainfall during each month? And third, were the 1998 relationships between the NBI and these atmospheric features repeated during periods in the historical record when joint variations between blocking and YRV rainfall mirrored those identified in 1998? The ability to answer these questions will greatly increase our ability to diagnose, and ultimately forecast, the circulation patterns that cause YRV excessive rainfall.

Acknowledgements. The authors wish to thank Drs. Dale P. Kaiser, Peter J. Robinson and Kenneth R. Sperber for their many helpful comments on an earlier version of this paper. We are also grateful to the anonymous reviewers for their suggestions.

\section{LITERATURE CITED}

Chang CP, Chen GT (1995) Tropical circulations associated with southwest monsoon onset and westerly surges over the South China Sea. Mon Weather Rev 123:3254-3267

Chang CP, Hou SC, Kuo HC, Chen GTJ (1998) The development of an intense east Asian summer monsoon disturbance with strong vertical coupling. Mon Weather Rev 126:2692-2712

Chang CP, Zhang Y, Li T (2000a) Interannual and interdecadal variations of the east Asian summer monsoon and tropical SSTs. Part I: Roles of the subtropical ridge. J Clim 13:4310-4325

Chang CP, Zhang Y, Li T (2000b) Interannual and interdecadal variations of the east Asian summer monsoon and tropical SSTs. Part II: Meridional structure of the monsoon. J Clim 13:4326-4340

Chen YL, Li J (1995) Large-scale conditions favorable for the development of heavy rainfall during the TAMEX IOP3. Mon Weather Rev 123:2978-3002

Ding YH (1994) Monsoons over China. Kluwer Academic Press, New York

Fan Z, Oglesby RJ (1996) A 100-yr. CCM1 simulation of north China's hydrologic cycle. J Clim 9:189-204

Kalnay E, Kanamitsu M, Collins W, Deaven D and 17 others (1996) The NCEP/NCAR 40-year reanalysis project. Bull Am Meteorol Soc 77:437-471

Lau KM, Weng H (2001) Coherent modes of global SST and summer rainfall over China: an assessment of the regional impacts of the 1997-98 El Niño. J Clim 14:1294-1308

Lau KM, Wu HT (2001) Principal modes of rainfall-SST vari-

Editorial responsibility: Robert Davis,

Charlottesville, Virginia, USA ability of the Asian summer monsoon: a reassessment of the monsoon-ENSO relationship. J Clim 14:2880-2895

Lau KM, Yang GJ, Shen SH (1988) Seasonal and intraseasonal climatology of summer monsoon rainfall over East Asia. Mon Weather Rev 116:18-37

Lau KM, Kim KM, Yang S (2000) Dynamical and boundary forcing characteristics of regional components of the Asian summer monsoon. J Clim 13:2461-2482

Liang XZ, Wang WC (1998) Associations between China monsoon rainfall and tropospheric jets. Q J R Meteorol Soc 124:2597-2623

Liang XZ, Samel AN, Wang WC (1995) Observed and simulated decadal variability in monsoon rainfall in China. Clim Dyn 11:103-114

Liang XZ, Wang WC, Samel AN (2001) Biases in AMIP model simulations of the east China monsoon system. Clim Dyn 17:291-304

Ma KY, Bosart LF (1987) A synoptic overview of a heavy rain event in southern China. Weather Forecast 2:89-113

National Climatic Data Center (1999) The NCDC Global Surface Summary of the Day dataset. National Climatic Data Center, Asheville, NC

Ninomiya K, Akiyama T (1992) Multi-scale features of Baiu, the summer monsoon over Japan and east Asia. J Meteorol Soc Jpn 70:467-495

Nitta T, Hu ZZ (1996) Summer climate variability in China and its association with $500 \mathrm{hPa}$ height and tropical convection. J Meteorol Soc Jpn 74:425-445

Samel AN, Wang SW, Wang WC (1995) A comparison between observed and GCM simulated summer monsoon characteristics over China. J Clim 8:1690-1696

Samel AN, Wang WC, Liang XC (1999) The monsoon rainband over China and relationships with the Eurasian circulation. J Clim 12:115-131

Shen X, Kimoto M, Sumi A, Numaguti A, Matsumoto J (2001) Simulation of the 1998 East Asian Summer Monsoon by he CCSR/NIES AGCM. J Meteorol Soc Jpn 79:741-757

Tao S, Chen L (1987) A review of recent research on the east Asia summer monsoon in China. In: Krishnamurti TN (ed) Monsoon meteorology. Oxford University Press, New York, p 60-92

Tao S, Fu C, Zeng Z, Zhang QY (1991) Two long-term instrumental climate data bases of The Peoples Republic of China. In: US Department of Energy (ed) Publication 3747. Environmental Sciences Division, Oak Ridge, TN

Weng, HY, Lau KM, Xue YK (1999) Multi-scale summer rainfall variability over China and its long-term link to global sea-surface temperature variability. J Meteorol Soc Jpn $77: 845-857$

Yatagai A, Yasunari T (1995) Interannual variations of summer precipitation in the arid/semi-arid regions of China and Mongolia: their regionality and relation to the Asian summer monsoon. J Meteorol Soc Jpn 73:909-923

Submitted: December 5, 2001; Accepted: July 2, 2002

Proofs received from author(s): January 6, 2003 